\title{
Time-lapse monitoring of an electrokinetic soil remediation process through frequency-domain electrical measurements
}

\author{
Michele Cercato and Giorgio De Donno* \\ "Sapienza" University of Rome - DICEA Via Eudossiana 18, 00184 Rome, Italy \\ *corresponding author: giorgio.dedonno@uniroma1.it
}

\begin{abstract}
The electrokinetic (EK) method is an emerging technique for soil remediation, even though a monitoring system of the contaminant removal through geophysical methods has not been developed yet. In this paper, frequency-domain time-lapse measurements are used on heavymetal contaminated sediments for monitoring an EK remediation process in a small-scale measuring cell. Our goal is to monitor the development of the electrokinetic process within the sediment and to evaluate the total time needed for the treatment. In fact, frequency-domain electrical monitoring provides complex resistivity spectra at different time steps that can be correlated to any changes in the physical properties of the sediments. We perform laboratory spectral induced polarization (SIP) measurements on different samples before, during and after the EK treatment, using different electrolyte solutions (acids and tap water), commonly employed in EK remediation. Direct-current measurements (resistivity and chargeability) were also acquired on one sample for testing the reliability of the system by a comparison with a widespread commercial instrumentation for field measurements.
\end{abstract}

Results indicate that resistivity is a diagnostic parameter as long as it is linked to changes in water saturation, $\mathrm{pH}$ and ionic concentration and not to the percentage of metal extraction. The resistivity exhibited well-defined signatures as a function of time that changes depending on the conditioning agent and the grain size distribution. These peculiarities were used to understand the physical processes occurring within the cell and consequently to assess the effectiveness of the electrokinetic treatment.

Conversely, the polarization effect was negligible using acids as conditioning agents at the electrolyte chamber. Therefore, the SIP method is not effective under these conditions, being the polarization effect significant only when tap water was used at both ends of the measuring cell. In this case, we were able to correlate changes in water saturation with the time-shift observed on relaxation time distributions (RTDs) after inversion of SIP data and to observe, using normalized chargeability, that polarization is stronger at high $\mathrm{pH}$ values.

On these basis, resistivity is suitable to monitor the development of the remediation, to optimise the energy levels required for treatment and to assess the end time of the EK process (time when metal mobilization ends). In fact, the end time of treatment can be associated with the time at 
which resistivity becomes stable. This time is highly dependent on the particular working conditions and sediment grain size as demonstrated by our experiments.

keywords: SIP; soil monitoring; electrical resistivity; Debye decomposition; electrokinetic treatment

\section{Introduction}

The contamination of large areas by heavy metals and organic compounds has a huge impact on the environment: over the past last decades, substantial research has been focused on finding new solutions to remove contaminants from soil and groundwater. The electrokinetic (EK) method is one of the emerging technique for soil remediation, even though its application is not widespread (Virkutyte et al., 2002). In the EK remediation process, the pollutant removal is achieved by applying an electric field through an electrode pair (anode and cathode), thereby favouring the transport of pollutants toward the electrodes, through electromigration, electroosmosis and electrophoresis (e.g. Acar and Alshawabkeh, 1993). The EK method is minimally invasive (it only needs to ground two electrodes within common wells) and flexible, as it can be used both on site and/or in the laboratory for treating sediments with organic and inorganic contamination also in combination with other remediation methods (Kim et al., 2005). In particular, growing attention has been paid to EK remediation for the removal of heavy metals as few of in situ soil remediation techniques can deal with this target (Virkutyte et al., 2002; Hashim et al., 2011). In spite of that, there are numerous drawbacks and open problems still not fully addressed, which limit its applicability in the field, such as: i) the strong dependence on acidic conditions; ii) the cost-effectiveness in terms of total time needed for the remediation; iii) the requirement of a conducting pore fluid to mobilise contaminants; iv) the ambiguous response of the method for different grain size distributions (Sogorka et al., 1998). Since the pollutants have to be converted into mobile ionic forms, the soil needs to be saturated by a suitable electrolyte solution, which facilitates the mobilization of pollutants (Vocciante et al., 2016). The global effectiveness of the EK remediation process is almost only evaluated by a simple comparison between the pollutant concentration before and after the treatment at the electrode wells or by discrete sampling during the treatment at few points (Suthersan and Payne, 2004). In this sense, monitoring the whole remediation process both in space and time by piecewise parameters might improve our understanding of the geochemical process occurring within the subsurface due to the treatment.

Geoelectrical methods can be a proper choice for such purpose, because the electrical resistivity is a proxy for evaluating any changes in the degree of saturation and electrolyte solution. 
However, the removal rate of specific heavy metal species cannot been assessed through bulk resistivity, mainly because of the low ratio between the pollutant and the host sediment volume. Geoelectrical monitoring is generally performed using direct current (DC) or alternate current (AC) sources in the time- or frequency-domain. The integration of time-domain resistivity and induced polarization (TDIP) has been surely the most applied method for environmental applications (e.g. De Donno and Cardarelli, 2017a; Gazoty et al. 2012) during recent years. Multichannel acquisition of resistivity and IP data is now a robust and standardized technique for the characterization of contaminated sites (e.g. Dahlin et al., 2002) and monitoring remediation processes (e.g. Chambers et al., 2010). Some examples of application of timedomain electrical measurements have been reported in literature also for monitoring an EK remediation process (e.g. West et al., 1999). Once a multi-electrode dataset has been acquired, the resistive and capacitive behaviour of the subsoil is usually reconstructed by means of a tomographic image of the subsoil, where resistivity and integral chargeability are often used as model parameters. However, an efficient IP inversion should also consider the actual transmitter waveform, as well as the receiver transfer function to extract the spectral information contained within the IP decay curve (Fiandaca et al., 2012).

Spectral Induced Polarization (SIP) can be also investigated by AC measurements of amplitude and phase shift of the complex resistivity over a low-frequency range (generally $10^{-3}-10^{3} \mathrm{~Hz}$ ), in order to retrieve the physical properties of the sediments (Kemna et al., 2012) or to reconstruct a tomographic image of the contaminated subsoil (e.g. De Donno and Cardarelli, 2017b; Flores-Orozco et al., 2011). The SIP method has been applied to the detection of inorganic and organic contaminants (Börner et al., 1993; Schmutz et al., 2010; Vanhala, 1997), prediction of hydrogeological properties (Binley et al., 2005; Koch et al., 2010; Weller et al., 2015), monitoring the effect of microbial processes (Ntarlagiannis et al., 2005; Personna et al., 2008; Williams et al., 2005), bioremediation of aquifers (Flores-Orozco et al., 2011) and hydrocarbon contaminated sites (Mewafy et al., 2013). SIP applications at the field scale are still time-consuming and more sensible to the induction phenomena compared to standard timedomain acquisitions (Maurya et al., 2018) and EK remediation has been rarely applied at the field scale (e.g. Kim et al., 2011). Therefore, research in this field so far has mainly focused on laboratory studies in an effort to analyze potential and limits of the geoelectrical measurements for monitoring an EK remediation process. Masi and Losito (2015) presented a laboratory application of the SIP method before and after an electrokinetic remediation of metalcontaminated marine sediments. The authors found a good correlation between the chargeability and the $\mathrm{pH}$, due to the EDL polarization. This is caused by the alteration of the 
zeta potential due to $\mathrm{pH}$ changes induced by the transport of $\mathrm{H}^{+}$ions during the remediation experiments. However, since the measurements were acquired outside the EK apparatus by extracting small samples from the sediments, it was not possible to monitor continuously the treatment with SIP measurements. Such information is pivotal to monitor the development of the electrokinetic process within the sample and to evaluate the total time needed for the treatment.

For these reasons in this work, a measurement system is developed for time-lapse frequencydomain electrical monitoring of an electrokinetic remediation of metal-contaminated marine sediments. We perform electrical measurements before, during and after treatment over different samples, treated using different electrolyte solutions.

\section{Materials and methods}

\subsection{Time-lapse spectral induced polarization}

The resistive and capacitive response of a medium to an external current stimulation is defined by the Ohm's law:

$\mathbf{J}=\frac{\mathbf{E}}{\rho^{*}(\omega)}=\frac{\mathbf{E}}{\rho^{\prime}(\omega)+i \rho^{\prime \prime}(\omega)}$,

where $i=\sqrt{-1}, \mathbf{J}$ and $\mathbf{E}$ are current density and electric field vectors and $\rho^{*}$ is the complex electrical resistivity, that generally depends on the angular frequency $\omega=2 \pi f$, being $f$ the frequency. The real part of the complex resistivity $\left(\rho^{\prime}\right)$ is related to the electrolytic conduction in the bulk pore solution, while the imaginary part $\left(\rho^{\prime \prime}\right)$ is associated to the electrochemical polarization mechanisms. For environmental applications operating over the above mentioned low-frequency range $\left(<10^{3} \mathrm{~Hz}\right)$, the polarization is mainly due to the ionic charge separation associated with the electrical double layer (EDL) that exists at the mineral-fluid interface (Binley et al., 2005).

The complex electrical resistivity is generally obtained from the injected current $I^{*}$ and the electric potential $V^{*}$, which are both complex quantities, by:

$\rho^{*}\left(\omega_{j}\right)=K \frac{V^{*}\left(\omega_{j}\right)}{I^{*}\left(\omega_{j}\right)}=K Z^{*}\left(\omega_{j}\right)=K\left|Z^{*}\left(\omega_{j}\right)\right| e^{-i \varphi\left(\omega_{j}\right)}$,

where $K$ is the so-called geometric factor depending on the particular array and electrode arrangement, $\mathrm{Z}^{*}$ is the complex electrical impedance that can be expressed in terms of amplitude $|Z|$ and phase shift $\varphi$, and $j=1, \ldots, N_{f}$ with $N_{f}$ the number of given frequencies. When polarization occurs, the phase shift is negative. Therefore, using a sample having length $L$ and cross-sectional area $A$, we can measure both amplitude $|\rho|$ and phase shift $\varphi$ of the complex resistivity over a certain frequency range, as: 
$\left|\rho^{*}\left(\omega_{j}\right)\right|=\frac{A}{L}\left|Z\left(\omega_{j}\right)\right|[\Omega \mathrm{m}]$

$137 \varphi\left(\omega_{j}\right)=10^{3} \arctan \left[\frac{Z^{\prime \prime}\left(\omega_{j}\right)}{Z^{\prime}\left(\omega_{j}\right)}\right][\mathrm{mrad}]$.

138 The frequency dependence of the complex resistivity is generally described by phenomenological models as the Debye (Debye, 1929) and Cole-Cole (Cole and Cole, 1941; Pelton et al., 1978) models. However, recent studies have demonstrated that it is useful to split the polarization effect into several separate relaxation processes, since they are generally caused by different charging and discharging phenomena (e.g. Nordsiek and Weller, 2008). This approach, referred to as Debye decomposition (Morgan and Lesmes, 1994), is based on the superposition of the responses of a large number of Debye relaxation terms, in order to determine a relaxation time distribution (RTD) (Weigand and Kemna, 2016):

$\rho^{*}(\omega)=\rho_{0}\left(1-\sum_{k=1}^{N_{\tau}} m_{k}\left[1-\frac{1}{1+i \omega \tau_{k}}\right]\right)$,

where $\rho_{0}$ is the direct-current (DC) resistivity, $N_{\tau}$ is the number of relaxation times, $m_{k}$ is the chargeability corresponding to the relaxation times $\tau_{k}$.

In this work, we employed the inverse approach after Weigand and Kemna (2016), where the integral parameters can be eventually calculated for each time-step. Among them, we chose four parameters as being diagnostic for the electrokinetic remediation process:

- the DC resistivity $\rho_{0}$;

- the total chargeability $m_{T O T}=\sum_{k=1}^{N_{\tau}} m_{k}$, that is sensitive to the ratio of surface conductivity to bulk conductivity effects (e.g. Lesmes and Frye, 2001);

- the normalized chargeability $m_{T O T}^{N}=m_{T O T} / \rho_{0}$, that carries information about the

\subsection{Experimental set-up}

The experimental holder used for the EK remediation experiments is a Plexiglas prismatic cell $500 \mathrm{~mm}$ long, $100 \mathrm{~mm}$ wide and $80 \mathrm{~mm}$ high. The cell is divided into three main compartments, the middle one designed for hosting the sediment, while electrolyte solutions fill up the anode and cathode compartments (Fig. 1). 

The electrolyte level inside the chambers was kept constant by replacing the solutions every 7 days. The electrodes, placed at the end of each electrolyte compartment, are mixed metal oxide (MMO) titanium-coated meshes $(100 \times 80 \times 2 \mathrm{~mm})$, both at the anode and at the cathode. The sediment and the electrolyte solutions are separated by a nylon grid (mesh size $2 \mathrm{~mm}$ ) and filter paper. The size of sediment compartment is $300 \times 100 \times 280 \mathrm{~mm}$, for a total volume of $2.4 \mathrm{dm}^{3}$. The device was provided with four drainage pipes, aiming to sample the electrolyte solution during the EK process. Unfortunately, the total volume of collected solution was too low to allow chemical analysis during the treatment. The electrodes are connected to a power supply capable of operating under a DC constant current density of $20 \mathrm{~A} / \mathrm{m}^{2}$. A simple sketch of the laboratory experiment is given in Fig. 2.

\subsection{Samples preparation}

The marine sediments used in the experiments were dredged from three different harbours (named as A, B and C) in Southern (A1, A2 and A3) and Central Italy (B1, C1 and C2). After dredging, the material was stored under controlled conditions (temperature and humidity) to ensure the stability of physicochemical properties. For chemical and physical characterization, it was air-dried at a temperature $\sim 20^{\circ} \mathrm{C}$ and sieved to remove the fraction above $2 \mathrm{~mm}$. The particle-size distribution up to $12 \mathrm{~mm}$, is shown in Fig. 3, where differences among samples from the "A" site are negligible. All samples are characterized by a strong percentage of silt and sand with a lower clay percentage (around 10\%), except for the A and C2 samples (around $20 \%$ ). They can be classified as a poorly sorted sandy silt with clay. The elemental composition of the different samples before treatment, reported in Tab. 1, was evaluated using the procedure after Iannelli et al. (2015)

\begin{tabular}{c|c|c|c|c} 
Element & $\begin{array}{c}\text { A1, A2, A3 } \\
\text { (average values) }\end{array}$ & B1 & C1 & C2 \\
\hline $\mathrm{Ca}$ (g/kg dry wt.) & $57.4 \pm 3.7$ & $71.9 \pm 7.4$ & $17.5 \pm 1.0$ & $23,1 \pm 0.8$ \\
\hline $\mathrm{Mg}(\mathrm{g} / \mathrm{kg}$ dry wt.) & $19.9 \pm 1.3$ & $9.0 \pm 0.7$ & $4.4 \pm 0.2$ & $7,5 \pm 0.3$ \\
\hline $\mathrm{Fe}(\mathrm{g} / \mathrm{kg}$ dry wt.) & $45.7 \pm 3.4$ & $16.0 \pm 2.4$ & $10.6 \pm 1.4$ & $18,0 \pm 1.3$ \\
\hline $\mathrm{Cd}(\mathrm{mg} / \mathrm{kg}$ dry wt. $)$ & $0.7 \pm 0.1$ & $0.74 \pm 0.18$ & $0.3 \pm 0.2$ & $0,30 \pm 0.04$ \\
\hline $\mathrm{Cr}(\mathrm{mg} / \mathrm{kg}$ dry wt.) & $103.1 \pm 3.5$ & $82.2 \pm 28.5$ & $46.9 \pm 5.4$ & $62,6 \pm 5.7$ \\
\hline $\mathrm{Cu}(\mathrm{mg} / \mathrm{kg}$ dry wt.) & $99.8 \pm 2.9$ & $17.5 \pm 4.3$ & $15.0 \pm 6.0$ & $9,6 \pm 7.4$ \\
\hline $\mathrm{Ni}(\mathrm{mg} / \mathrm{kg}$ dry wt.) & $18.4 \pm 9.9$ & $31.9 \pm 6.7$ & $76.5 \pm 11.0$ & $99,5 \pm 13.6$ \\
\hline $\mathrm{Pb}(\mathrm{mg} / \mathrm{kg}$ dry wt.) & $129.6 \pm 12.0$ & $32.1 \pm 5.4$ & $0.400 \pm 0.002$ & $0,400 \pm 0.003$ \\
\hline $\mathrm{Zn}(\mathrm{mg} / \mathrm{kg}$ dry wt.) & $317.9 \pm 9.8$ & $91.6 \pm 12.2$ & $37.0 \pm 7.2$ & $76,1 \pm 3.7$
\end{tabular}


The EK experiments were carried out with different conditions for the six samples analyzed, as reported in Tab. 2. Our aim was:

- to compare the influence of different electrolyte solutions at the cathode on the same sediment (A1, A2 and A3 experiments);

- to assess the role of different particle size distributions using the same electrolyte solutions on different samples (A2 and B1);

- to evaluate the effect of acids, employed both at anode and cathode, on different samples (C1 and $\mathrm{C} 2)$.

\begin{tabular}{c|c|c|c} 
Experiment & $\begin{array}{c}\text { Duration } \\
{[\text { days }]}\end{array}$ & Anolyte & Catholyte \\
\hline A1 & 35 & Tap water & Tap water \\
\hline A2 & 90 & Tap water & 0.2 M Nitric acid \\
\hline A3 & 90 & Tap water & 0.2 M Hydrochloric acid \\
\hline B1 & 90 & Tap water & 0.2 M Nitric acid \\
\hline C1 & 90 & 0.2 M Nitric acid & 0.2 M Nitric acid \\
\hline C2 & 90 & 0.2 M Nitric acid & 0.2 M Nitric acid
\end{tabular}

Table 2. Experimental conditions for the six experiments.

Nitric and hydrochloric acid solutions (resistivity $\approx 0.1 \Omega \mathrm{m}$ ) were employed to control the $\mathrm{pH}$ of the electrolytes and to achieve the acidification of the sediment for contaminant solubilisation. In fact, using water alone may be not effective for heavy metal removal, because the precipitation of species occurring near the cathode (e.g. $\left.\mathrm{Pb}(\mathrm{OH})_{2}\right)$, due to hydroxide ions generated by electrolysis reaction, cannot be avoided (Reddy and Cameselle, 2009).

At the end of each test, each sample section was tested for water content, $\mathrm{pH}$ and metal concentration, following the procedures after Iannelli et al. (2015). The metal mobilization of the main contaminants was then calculated as the percentage ratio between the overall mass of metal mobilized from the sample and the corresponding initial mass in the sediment (Iannelli et al., 2015). The amount of metal mobilized is the sum of the amount of metal detected in the two electrolytes chambers. The results are listed in Tab. 3, for the six experiments performed. The higher is the metal mobilisation ratio, the more effective is the EK process.

\begin{tabular}{c|c|c|c|c|c|c|c} 
Experiment & $\mathrm{Fe}$ & $\mathrm{Cd}$ & $\mathrm{Cr}$ & $\mathrm{Cu}$ & $\mathrm{Ni}$ & $\mathrm{Pb}$ & $\mathrm{Zn}$ \\
\hline $\mathrm{A} 1$ & 0.3 & 0.03 & 1.10 & 0.70 & 1.60 & 0.10 & 0.20 \\
\hline $\mathrm{A} 2$ & 4.9 & 10.1 & 15.0 & 27.4 & 44.3 & 10.4 & 23.0 \\
\hline $\mathrm{A} 3$ & 23.3 & 34.6 & 11.6 & 11.6 & 19.4 & 13.7 & 22.7 \\
\hline $\mathrm{B} 1$ & 17.2 & 28.6 & 10.6 & 35.6 & 66.6 & 17.0 & 17.6 \\
\hline $\mathrm{C} 1$ & 31.7 & 24.7 & 9.7 & 60.6 & 89.7 & 46.1 & 46.4 \\
\hline $\mathrm{C} 2$ & 18.6 & 9.3 & 6.0 & 33.5 & 38.2 & 36.2 & 27.1
\end{tabular}


The results shown in Tab. 3 demonstrate that using water is not effective for metal mobilization, whereas nitric acid performs better for $\mathrm{Cu}, \mathrm{Ni}$ and $\mathrm{Pb}$ than hydrochloric acid, which conversely allows larger $\mathrm{Cd}$ and $\mathrm{Fe}$ mobilization.

\subsection{Electrical measurements}

The six samples were all tested using time-lapse AC electrical measurements, by stopping the EK treatment for about 10 minutes, which is the average time needed for the geophysical measurements.

The AC experimental instrument used in this work is the SipLabII by Radic Research ${ }^{\odot}$, capable of measuring the frequency dependence of complex resistivity (amplitude and phase) of rocks and sediments over the $1 \mathrm{mHz}-12 \mathrm{kHz}$ range. Measurements were acquired using the same electrodes employed for the EK experiments as current electrodes (MMO titanium-coated mesh) and gold electrodes as four receiver pairs spaced $6 \mathrm{~cm}$ apart (Figs. 1 and 2). Polarization effect were mitigated by inserting electrodes only $0.5 \mathrm{~mm}$ within the sample (Fig. 2), that is the minimum electrode depth required to ensure a sufficiently low $(<1 \mathrm{k} \Omega)$ contact resistance. Although non-polarizable (e.g. $\mathrm{Ag} / \mathrm{AgCl}$ ) can theoretically cancel out the latter effect, they are easily contaminated and difficult to clean (Vanhala and Soininen, 1995), especially when measuring contaminated fine-grained samples at low $\mathrm{pH}$ levels, as in this study. Consequently, we have four measurements for each time step, each related to different sample sections (S1, S2, S3 and S4 in Fig. 1). Considering the geometry of the sample holder and the estimated resistivity of the investigated media, we set the amplitude of the input voltage at $3 \mathrm{~V}$, with a resulting current ranging from 3 to $5 \mathrm{~mA}$, depending on the investigated sample. For SIP measurements, we chose a frequency range between $188 \mathrm{mHz}$ and $100 \mathrm{~Hz}$, lower enough to avoid the effect of the EM coupling occurring at higher frequencies $(>100 \mathrm{~Hz})$. In this range, the measured impedance (amplitude and phase) has proven to be stable and repeatable. Amplitude and phase of the complex resistivity of a single sample section can be found for each angular frequency $\omega_{j}$ using eq. (3), with $A=h \cdot l$, being $h$ and $l$ sample height and length and $L$ is the distance between the two potential electrodes $($ fixed $=60 \mathrm{~mm}$ ). Measurements were acquired before, during (every 7 days) and after the treatment (90 days). Only for the A2 experiment, we also used time-domain AC measurements acquired with the IRIS Instruments SyscalPro48 resistivimeter using the same electrodes and configurations described above for the AC measurements, with the aim to compare the AC laboratory 
instrument with a DC instrument directly usable for electrokinetic remediation monitoring at the field scale. We set the amplitude of the input voltage at $12 \mathrm{~V}$ (minimum available value resulting current ranging from 10 to $50 \mathrm{~mA}$ ), with a current injection time of $2 \mathrm{~s}$ (8 stacks), a time-delay of $40 \mathrm{~ms}$ and a semi-logarithmic sampling of the IP decay curve using 20 gates, having a length of $40 \mathrm{~ms}$ for gates no.1-7, $80 \mathrm{~ms}$ for gates no.8-14 and $160 \mathrm{~ms}$ for gates no.1520. In this range, the measurements has proven to be stable and repeatable. DC resistivity $\rho$ and integral chargeability $m$ of a single sample section are found as:

$\rho=\frac{\Delta V}{I} \frac{A}{L}[\Omega \mathrm{m}]$,

$m=\frac{10^{3} \int_{t i}^{t f} V^{R} d t}{\Delta V \Delta t}[\mathrm{mV} / \mathrm{V}]$

where $\Delta V$ is the measured voltage during application of the DC current $I$ and $V^{R}$ the residual voltage after termination of the applied current integrated over a time window $\Delta t$ defined between times $t_{i}$ and $t_{f}$.

\subsection{System calibration}

The experimental system was calibrated by analysing: i) the reliability of the whole system (device, holder, electrodes) by time- and frequency-domain measurements on a tap water sample having known resistivity; ii) the effect of the drainage pipes on the electrical measurements; iii) the effect of diffusion on time-lapse electrical data, in the absence of electric field applied for remediation.

The reliability of the system was tested using tap water having a known resistivity at $20^{\circ} \mathrm{C}$ (around $21.2 \Omega \mathrm{m}$ ). The resulting amplitude and phase spectra are shown in Fig. 4. Amplitude varies between 21.2 and $21.8 \Omega \mathrm{m}$, a range slightly higher than expected, with a maximum deviation of $0.3 \Omega \mathrm{m}$ ( $2 \%$ of the mean value). The increase of phase values at frequencies above $100 \mathrm{~Hz}$, in mainly due to the electromagnetic (EM) coupling, while for lower frequency the maximum deviation from the expected value (as the polarization of water is theoretically null in the low-frequency range) is $0.5 \mathrm{mrad}$, due to a residual polarization of the potential electrodes.

The effect of the drainage pipes on the resistivity value were assessed by both AC frequencydomain and DC time-domain measurements performed with and without the pipes. The results, reported in Tab. 4, clearly show that without the pipes the mean amplitude at $1.46 \mathrm{~Hz}$ and the mean DC resistivity values are similar to the expected resistivity of tap water and the maximum error committed by adding the pipes is around $2 \%$. Phase and chargeability values are not significantly affected by the presence of the pipes. The SIP results achieved in the 
frequency range between $188 \mathrm{mHz}$ and $100 \mathrm{~Hz}$ are comparable to those at $1.46 \mathrm{~Hz}$ and are not shown for the sake of simplicity.

\begin{tabular}{c|c|c|c|c|c|c|c|c} 
& \multicolumn{4}{|c|}{ With pipes } & \multicolumn{4}{c}{ Without pipes } \\
\cline { 2 - 9 } Section & $\begin{array}{c}\text { Amplitude } \\
{[\Omega \mathrm{m}]}\end{array}$ & $\begin{array}{c}\text { Phase } \\
{[\mathrm{mrad}]}\end{array}$ & $\begin{array}{c}\text { DC } \\
\text { Resistivity } \\
{[\Omega \mathrm{m}]}\end{array}$ & $\begin{array}{c}\text { Chargeability } \\
{[\mathrm{mV} / \mathrm{V}]}\end{array}$ & $\begin{array}{c}\text { Amplitude } \\
{[\Omega \mathrm{m}]}\end{array}$ & $\begin{array}{c}\text { Phase } \\
{[\mathrm{mrad}]}\end{array}$ & $\begin{array}{c}\text { Resistivity } \\
{[\Omega \mathrm{m}]}\end{array}$ & $\begin{array}{c}\text { Chargeability } \\
{[\mathrm{mV} / \mathrm{V}]}\end{array}$ \\
\hline S1 & 21.78 & 0.72 & 21.46 & -0.52 & 21.40 & 0.85 & 21.43 & -0.42 \\
\hline S2 & 21.52 & 0.06 & 20.60 & 0.13 & 21.16 & 0.00 & 20.40 & 0.10 \\
\hline S3 & 21.44 & -0.52 & 21.13 & 0.05 & 21.19 & -0.47 & 20.79 & 0.01 \\
\hline S4 & 21.16 & 0.37 & 20.80 & 0.30 & 20.86 & 0.33 & 20.31 & 0.25
\end{tabular}

Table 4. Resistivity and phase values recovered with and without pipes using the AC system at the frequency of $1.46 \mathrm{~Hz}$ (amplitude and phase) and a DC system (resistivity and chargeability).

Finally, it is reasonable to suppose that the resistivity of the sample changes with time even without an external field applied when working with acid solutions or tap water at the anode and cathode, mainly due to the diffusion of these solutions. Consequently, the composition of the electrolyte solution of the marine sediment may change with detectable variations in resistivity. Therefore, we tested the "A" sediment without an applied field, only replacing the solutions every 7 days, such as we did for the other EK experiments. The outcomes, shown in Fig. 5 for AC measurements only, demonstrate that the resistivity is increased near the anode (S1 and S2 sections), due to the diffusion of tap water (more resistive), while the nitric acid (more conductive) is responsible for the amplitude decrease seen near the cathode (S3 and S4 sections). This effect must be taken into account when analysing the results of an electrokinetic experiment. Conversely, there are no significant effects on the phase values.

\section{Results}

In Fig. 6 the variation of pH (Fig. 6a) and water saturation (Fig. 6b) are displayed as a function of the distance from the anodic end, before ( 0 subscript) and after treatment for the six EK experiments. We can identify three main trends referred to the three different conditioning agents at the cell ends: i) high pH values (11.5) at the cathode and low (around 7) at the anode when water is used (A1 sample); ii) slightly low $\mathrm{pH}$ (5-6) at both ends with acids only at the cathode (A2, A3 and B1 samples) and iii) low $\mathrm{pH}$ (3-5) at both ends with acids at both electrolyte compartments (C1 and C2) samples). The high variability for natural water saturation before treatment (from 15 to $35 \%$ as a function of the different geographical locations) is reduced at the end of the experiments, when a quite homogenous value is found for all samples (around 25-30\%), as a results of the strong influence of the external solutions. As mentioned before, we compared, only at the beginning of the tests (A2 experiment), the SIP results with independent DC measurements. An example is shown in Fig. 7, where the AC 
results (Figs. 7b,d) for the A2 experiment are compared with the respective DC ones (Figs. $7 \mathrm{a}, \mathrm{c}$,$) .$

Amplitude (Fig. 7a) and DC resistivity (Fig. 7b) exhibit similar behaviours with negligible differences (maximum deviations $<1 \%$ ). The amplitude/DC resistivity curves can be referred to three main stages: a resistivity increase during the first few days (0-14 days) followed by a sharp decrease of the resistivity (14-42 days) and a slow reduction (42-90 days) until the end of the experiment, when resistivity reaches almost a constant value. The initial increase in resistivity near the anode is likely due to the depletion of $\mathrm{Na}^{+}$ions from the marine sediment that triggered the migration of $\mathrm{H}^{+}$ions (Kamran et al., 2012a; Iannelli et al., 2015). In this phase, the resistivity increase is speeded up (steeper slope of the amplitude-time curve) compared to the diffusion experiment (Fig. 5). This is expected, because electromigration is dominant under applied potential gradients (Kamran et al., 2012b). The acid front propagates towards the cathode but it is limited by the buffering capacity of the sediment and consequently a minor increase of resistivity is seen at the S2-S4 sections. Then (after 14 days), the resistivity drops abruptly in all the sample sections. This resistivity decrease firstly occurs at the S4 section (cathode) and then progressively develops towards the anode. The strong decrease of electrical resistivity is likely due to the nitrates from the catholyte. These can be easily transported toward the anode by electromigration, as their adsorption on the soil surface is negligible (Ryu et. al., 2009). In fact, the catholyte purging solution $\left(\mathrm{HNO}_{3}\right)$ supplied a huge amount of ions to the sample, which decrease electrical resistivity, as previously investigated by Ryu et al. (2009) on a pulsed electrokinetic experiment for decontamination of agricultural land.

Finally in the third phase (after 42 days), the anode resistivity is lower compared to the other three sections, as the above mentioned process may increase the ion concentration at the anode. The electrical resistivity reaches almost a constant value on the four sections and it is everywhere much lower than the initial value $(0.9 \Omega \mathrm{m})$, particularly at the anode. These results are consistent with those observed by Ryu et. al. (2009) using the same catholyte solution.

Conversely, both the integral chargeability (Fig. 7c) and phase (Fig. 7d) do not vary significantly with time and along the different sections ( $\pm 2 \mathrm{mV} / \mathrm{V}$ and $\pm 2 \mathrm{mrad}$, respectively). Therefore, the polarization effect due to the electrokinetic treatment is negligible or very hardly detectable under the operating conditions used in this work with acids at the electrolyte chambers. .

We present the results for the six experiments in terms of time-lapse (0-90 days) plots of amplitude (Fig. 8) and phase (Fig. 9) within the selected frequency range (188 mHz - $100 \mathrm{~Hz})$. The experiment on the A1 sample (Figs. 8a and 9a) terminates after 35 days because the sharp 
increase of resistivity observed near the anode prevented the current flow within the sample. The amplitude-time curves for the other five experiments (Figs. 8b-f) are similar in terms of shape and maximum resistivity range, even though there are some differences due to the different electrolyte solutions and textural composition of the different samples.

In detail, the A3 experiment (Fig. 8c, same sample of A2 operating with different catholyte solutions) exhibits a similar behaviour when compared to the A2 experiment. The most evident differences are the steeper slope of the resistivity drop observed for A2 after 14 days at the S1 section, compared to the A3 curve and the different trend of the four curves after 42 days. Differently from the early analysed A2 experiment (Fig. 8b), the resistivity of the anodic sections (S1, S2) for the A3 experiment (Fig. 8c) is higher than the respective cathodic ones $(\mathrm{S} 3, \mathrm{~S} 4)$ at the end of the experiment. This can be explained because the application of $\mathrm{HCl}$ introduces large amounts of $\mathrm{Cl}^{-}$ions into the solution, causing the production of $\mathrm{Cl}_{2}$ (chlorine gas) by electrolysis at the anode and consequently reducing the total amount of ions with respect to the A2 experiment.

Changing the type of sediment does not have a significant effect on the resistivity curves. This is confirmed by the B1 experiment (Fig. 8d), performed with the same electrolyte solutions of A2. The main visible change is the maximum peak of resistivity reached in the S1 section at the beginning of the experiment: the $\mathrm{S} 1$ and $\mathrm{S} 2$ sections have comparable resistivity values, which is the evidence of a higher speed of the $\mathrm{Na}^{+}$front. On the other hand, the amplitude drop is not completely run out at the end of experiment, differently from Fig. 8b. Both effects can be explained by the physical properties (porosity, tortuosity, etc.) of the B 1 sample that slightly differs from the A2 one, mostly regarding the less clay content, which can modify the sorption mechanisms, including adsorption and/or ion exchange on clay surfaces (Virkutyte et al. 2002). When the nitric acid is applied at both ends (Figs. 8e,f), the resistivity peak in the first phase of the experiments (0-14 days) cannot be observed, differently from Figs. 8b,d. With $\mathrm{HNO}_{3}$ at the anode, the $\mathrm{pH}$ lowers to 3-4, increasing the electrical conductivity of the anodic sections (S1, $\mathrm{S} 2$ ), with respect to the cathode. At the beginning of the experiment, the "C" sediments exhibit very low resistivity values $(0.3-0.4 \Omega \mathrm{m})$, as a results of a high salinity: therefore, it is reasonable that the depletion of $\mathrm{Na}^{+}$and $\mathrm{Cl}^{-}$ions can increase the resistivity near the cathode by lowering the ionic concentration and that the development of counter ions $\left(\mathrm{NO}_{3}^{-}\right)$is not sufficient to restore the initial concentration. As seen before, the role of grain size distribution seems to affect the speed of the process. In fact, the resistivity of the C2 sample (fine-graded) varies slowly during the EK treatment, as a result of a probable lower ionic mobility. Nevertheless, at 
the end of the treatment the lowest values are recorded near the anode, as for A2 and B1 experiments.

Without using any $\mathrm{pH}$ conditioning at the electrodes (A1), the amplitude curves display a completely different behaviour (Fig. 8a). This is not unexpected, because in this case $\mathrm{OH}^{-}$ions are free to develop at the cathode and to migrate toward the anode (alkaline front). Although the mobility of $\mathrm{H}^{+}$is higher when compared to $\mathrm{OH}^{-}$, the alkaline front migrated faster than the acid front because of the greater buffering capacity of the sediment towards acids rather than bases (Iannelli et al., 2015). Resistivity strongly increases in time at the S1 section (Fig. 8a) while in the other sections we observe only a slight increase and then a small decrease until the end of the experiment.

The respective phase time-lapse curves are represented in Fig. 9, where one can observe that no polarization occurs in all samples where acids have been used as conditioning agents (Figs. 9bf). In these cases, the phase values vary around zeros in a thin range ( $\pm 2 \mathrm{mrad})$, without showing any coherent trend in time. The only polarization effect is visible for the A1 experiment (Fig. 9a), where the phase reaches values up to $8 \mathrm{mrad}(\mathrm{S} 1)$ at the end of the experiment. Since the main polarization mechanism can be attributed to the EDL (Stern layer) polarization (Masi and Losito, 2015), the polarization should be stronger where pH is high (Lorenz, 1969; Mei et al., 2016). Therefore, the low $\mathrm{pH}$ conditions implemented on the other experiments prevents the observation of a clear capacitive effect. However, focusing on the A1 experiment, the polarization at the $\mathrm{S} 1$ section $(\mathrm{pH} \cong 7)$ should be lower than those at the adjacent ones $(\mathrm{pH} \cong$ 11.5).

In order to clarify this aspect, we performed time-lapse inversion of SIP data, following the Debye decomposition approach (eq. 4) on the A1 experiment, being the only one where polarization is visible. The observed SIP spectra are shown in Fig. 10 (amplitude) and Fig. 11 (phase) for the four sample sections, together with the respective fitted spectra at last iteration of the inversion procedure.

The amplitude spectra are nearly flat, as expected, while the phase spectra often present a single peak located at different frequencies as a function of sample position (section) and time. The results of SIP inversion are discussed in terms of integral parameters (Fig. 12) and RTDs at different time steps (Fig. 13).

The resistivity curves (Fig. 12a) are comparable to the amplitude ones (Fig. 8a) and therefore the comments made above on Fig. 8a apply also for Fig. 12a. The median relaxation time (Fig. 12b) remains almost constant around $5 \cdot 10^{-2} \mathrm{~s}$ along the different sections of the sample, as expected being $\tau_{50}$ linked to the textural proprieties of the sediment. The total chargeability 
(Fig. 12c) reflects the resistivity trend: $m_{T O T}$ is higher at $\mathrm{S} 1$ then at $\mathrm{S} 4$. However, the normalized chargeability should be a straightforward indicator of the effective polarization of the medium, capable to discern surface physico-chemical processes from bulk conductivity (Lesmes and Frye, 2001). In fact, we can see that after 35 days $m_{T O T}^{N}$ (Fig. 12d) is lower near the anode and higher elsewhere, reflecting the $\mathrm{pH}$ of the sediment at the end of the experiment. This confirms that polarization is stronger at high $\mathrm{pH}$ values.

The RTDs recovered for the four sample sections (Fig. 13) is shifted toward the high frequencies (low $\tau$ ) at increasing time steps. This effect might be caused by an increase of water saturation observed at the end of experiment (around 15\% higher than before treatment, Fig. 6b), according to the results shown both by Ghorbani et al. (2009) and Jougnot et al. (2010). They related this effect to textural changes and/or polarization process associated with the bound water in the micropores.

\section{Discussion}

To our knowledge we presented the first application of time-lapse SIP method to monitor an EK remediation process. Although the electrical DC resistivity cannot be correlated directly with the percentage of metal extraction, it can be certainly a parameter of interest to understand the physical processes undergo within the electrokinetic cell, because it can be linked to changes in water saturation, $\mathrm{pH}$ and ionic concentration. However, the interpretation of the variation of resistivity in time may be not straightforward. This is mainly due to the highly variability of the electrical response due to different grain size distributions and conditioning agents. The three situations analysed (without conditioning, with conditioning only at the cathode or with conditioning at both ends) have revealed recognizable signatures of the EK process. More specifically, without using acids in the electrolyte compartments, the resistivity tends to increase drastically near the anode, leading to a dramatic reduction of the current flow within the sample. This peculiar behaviour is consistent with the model proposed by Kamran et al. (2012a) for the same electrolyte solutions and a similar sample geometry. They demonstrated that the acidic region near the anode is formed by an excess of positively charged $\mathrm{H}^{+}$ions, which expels the also positively charged $\mathrm{Na}^{+}$ions. On the other hand, the alkaline front due to the production of $\mathrm{OH}^{-}$ions proceeds faster toward the cathode. Therefore, the acidic and alkaline fronts collides approximately at one third of the sample length and the $\mathrm{Na}^{+}$depletion front stagnates at this position. This collision results in a minimum of ions concentration, causing a decrease in the electrical conductivity at this position. In this case, the front position can be estimated being around $20-40 \%$ of the specimen length, that is the location of the 
interface between high and low resistivity and $\mathrm{pH}$ values. A secondary negative effect is the formation of metal hydroxides and the delay in metal extraction driven be the formation of $\mathrm{OH}^{-}$ ions at the cathode (e.g. Acar and Alshawabkeh, 1993).

Our data further confirm that the electrokinetic process is not effective when using water as electrolyte solution. Nevertheless, this is the only case where EDL polarization is observed, likely because of the higher $\mathrm{pH}$ values. These results are consistent with those observed by Masi and Losito (2015). In fact, they found an increase in polarization (chargeability) only with water at both ends (EXP1), while the use of acids at the cathode does not change the mean polarization of the specimen with respect to the initial value. Since the same effect is observed for the experiments with conditioning agents at both anodic and cathodic ends, the SIP technique is not effective for monitoring the electrokinetic experiment under these conditions.

Another important point, previously addressed by different researchers (e.g. Slater and Lesmes, 2002; Titov et al., 2010) is the role of normalized chargeability for assessing the effective polarization of the medium. It is recognized that the integral chargeability alone is not a diagnostic parameters for surface conductivity phenomena occurring within the EDL (Lesmes and Frye 2001). However, when normalized with the resistivity, it can reflect the effective magnitude of the polarization of the complex conductivity response, that is a function of the specific surface area, the surface charge density, and the effective surface ionic mobility of the ions in the EDL (Lesmes and Frye, 2001). In particular, the strong dependence of the normalized chargeability on the $\mathrm{pH}$ observed for the A1 sample is in agreement with previous work (Lesmes and Frye, 2001). The magnitude of the zeta potential, and consequently the magnitude of polarization, decreases with decreasing $\mathrm{pH}$ values, because more protons are available to occupy the free negative sites at the mineral surface, thus decreasing the negative surface charge density (see Hördt et al., 2016 for a theoretical review). In light of this, the role of $\mathrm{pH}$ is pivotal for assessing the feasibility of monitoring the EK process through SIP measurements, because working with low $\mathrm{pH}$ levels leads to a poor capability for SIP diagnostics. According to Ghorbani et al. (2009) the effect of an increasing water content due to the electrolyte solutions is reflected both on lowering the relaxation times (see Jougnot et al., 2010) and on increasing normalized chargeability (see Ulrich and Slater, 2004). They attributed the former effect to textural changes (more evident in desaturated samples as those investigated by the authors) and/or polarization process associated with the bound water in the micropores. The latter effect is visible also in our experiment (Fig. 12d), except for the S1 sections, where the acidification of the sample ( $\mathrm{pH}$ drops to 7) plays a predominant role. 
The peaks of the RTDs retrieved by the inversion of SIP using the Debye decomposition can be directly related to the spatial structure of the sediment, given the diffusion coefficient. Since the determination of the diffusion coefficient is not straightforward due to the multicomponent electrolyte, an estimation of the pore size distribution cannot be directly achieved. However, distinct diffusion coefficients produce distinct relaxation times (Revil and Florsch, 2010), that can be seen as multi-peaks in our RTDs or as a broader distribution of relaxations times (Figs. 13). In fact, multicomponent electrolyte is responsible for broader dispersion of the electrochemical polarization in the frequency domain, since the different mobilities of the counterions located in the Stern layer result in different main relaxation time constants (Revil and Florsch, 2010). The precipitation of species occurring near the cathode due to the massive presence of $\mathrm{OH}^{-}$ions seems to reduce this effect, leading to a single-peak RTD in the S4 section (Fig. 13d).

Although the phase cannot be used for monitoring an enhanced EK experiment with low $\mathrm{pH}$ levels, the resistivity seems to have a great diagnostic potential to monitor the effectiveness of the EK treatment, highlighting the following signatures: (1) an increase of resistivity near the anode at the beginning of the experiment could be mainly due to the $\mathrm{Na}^{+}$ions depletion; (2) an increase of conductivity could be due to the introduction of large amounts of counter ions; (3) the plateau seen on the resistivity curves at the end of the experiment can indicate that the EK treatment is completed and that no more species can be mobilized, under the operating conditions used in this work.

\section{Conclusions}

The results of time-lapse SIP measurements for monitoring an electrokinetic remediation process, pointed out the diagnostic potential and limits of the electrical measurements for understanding the EK treatment. The resistivity can be a diagnostic parameter as long as it is linked to changes in water saturation and ionic concentration and not to the percentage of metal extraction. The resistivity exhibited well-defined signatures as a function of time, but it strongly depends on the different conditioning agents and grain size distributions. These peculiarities can be used to understand the physical processes occurring within the cell and consequently to assess the effectiveness of the electrokinetic treatment.

Conversely, the polarization effect was negligible using acids as the conditioning agent at the electrolyte chamber. Therefore, the SIP method was not effective at low $\mathrm{pH}$ levels, being the polarization effect significant only when tap water was used at both ends of the electrokinetic cell. In this case, the inversion of SIP data allowed us: i) to obtain the RTDs that can be 
correlated with grain size distributions through the diffusion coefficient, if available; ii) to correlate the changes in water saturation with the time-shift observed on RTDs, iii) to confirm through the analysis of the normalized chargeability that polarization is stronger at high $\mathrm{pH}$ values, and iv) to observe a broadening of the RTD due to a multicomponent electrolyte solution. Therefore, if any polarization effect is detectable, we can improve the level of knowledge of the physical processing undergoing within the cell, though correlation of the electrical parameters with physical and chemical ones.

As far as field applications are concerned, the DC resistivity can represent a diagnostic parameter in order to monitor the development of the remediation, to optimise the energy levels required for treatment and to assess the end time of the EK process. The latter can be associated with the time step at which the electrical resistivity does no longer change in time. This value is highly dependent on the particular working conditions and sediment grain size as demonstrated by our experiments. However, when compared to field conditions, the assessment of the total time needed for remediation still represents a major issue that needs to be addressed by larger scale experiments.

\section{Acknowledgements}

This research is part of the SEKRET project (EU Life+ funding program). Prof. Alessandra Polettini, Prof. Raffaella Pomi and Dr. Angelo Marini (“Sapienza” University of Rome DICEA) are warmly thanked for their scientific contribution and for allowing us to perform geophysical measurements on EK treated samples. The authors wish also to thank Francesco Pugliese ("Sapienza" University of Rome - DICEA) for his technical support on laboratory measurements.

\section{References}

Acar, Y.B., Alshawabkeh, A.N., 1993. Principles of electrokinetic remediation. Environ. Sci. Technol. 27, 2638-2647.

Binley, A., Slater, L.D., Fukes, M., Cassiani, G., 2005. Relationship between spectral induced polarization and hydraulic properties of saturated and unsaturated sandstone. Water Resour. Res. 41, W12417.

Börner, F., Gruhne, M., Schön, J., 1993. Contamination indications derived from electrical properties in the low frequency range. Geophys. Prospect. 41, 83-98.

Chambers, J.E., Wilkinson, P.B., Wealthall, G.P., Loke, M.H., Dearden, R., Wilson, R., Allen, D., Ogilvy, R.D., 2010. Hydrogeophysical imaging of deposit heterogeneity and 
groundwater chemistry changes during DNAPL source zone bioremediation. J. Contam. Hydrol. 118(1), 43-61.

Cole, K.S., Cole, R.H., 1941. Dispersion and absorption in dielectrics I. Alternating current characteristics. J. Chem. Phys. 9(4), 341-351.

Dahlin, T., Bernstone, C., Loke, M.H., 2002. A 3-D resistivity investigation of a contaminated site at Lernacken, Sweden. Geophysics 67(6), 1692-1700.

Debye, P.J.W., 1929. Polar molecules. Chemical Catalog Company, Incorporated.

De Donno, G., Cardarelli, E., 2017a. Tomographic inversion of time-domain resistivity and chargeability data for the investigation of landfills using a priori information. Waste Manag. 59, 302-315.

De Donno, G., Cardarelli, E., 2017b. VEMI: a flexible interface for 3D tomographic inversion of time- and frequency-domain electrical data in EIDORS. Near Surf. Geophys. 15, 43-58.

Fiandaca, G., Auken, E., Christiansen, A.V., Gazoty, A., 2012. Time-domain-induced polarization: Full-decay forward modeling and 1D laterally constrained inversion of ColeCole parameters. Geophysics 77(3), E213-E225.

Flores-Orozco, A., Williams, K.H., Long, P.E., Hubbard, S.S., Kemna, A., 2011. Using complex resistivity imaging to infer biogeochemical processes associated with bioremediation of a uranium-contaminated aquifer. J. Geophys. Res. Biogeosci. 116, G03001.

Gazoty, A., Fiandaca, G., Pedersen, J., Auken, E., Christiansen, A.V., 2012. Mapping of landfills using time-domain spectral induced polarization data: the Eskelund case study. Near Surf. Geophys. 10(6), 575-586.

Hashim, M.A., Mukhopadhyay, S., Sahu, J.N., Sengupta, B., 2011. Remediation technologies for heavy metal contaminated groundwater. J. Environ. Manage. 92(10), 2355-2388.

Hördt, A., Bairlein, K., Bielefeld, A., Bücker, M., Kuhn, E., Nordsiek, S., Stebner, H., 2016. The dependence of induced polarization on fluid salinity and $\mathrm{pH}$, studied with an extended model of membrane polarization. J. Appl. Geophys 135, 408-417.

Jougnot, D., Ghorbani, A., Revil, A., Leroy, P., Cosenza, P., 2010. Spectral induced polarization of partially saturated clay-rocks: A mechanistic approach. Geophys. J. Int. 180(1), 210-224.

Iannelli, R., Masi, M., Ceccarini, A., Ostuni, M. B., Lageman, R., Muntoni, A., Polettini, A., Marini, A., Pomi, R., 2015. Electrokinetic remediation of metal-polluted marine sediments: experimental investigation for plant design. Electrochim. Acta 181, 146-159. 
Kamran, K., Van Soestbergen, M., Huinink, H.P., Pel, L., 2012a. Inhibition of electrokinetic ion transport in porous materials due to potential drops induced by electrolysis. Electrochim. Acta 78, 229-235.

Kamran, K., Pel, L., Sawdy, A., Huinink, H., Kopinga, K., 2012b. Desalination of porous building materials by electrokinetics: an NMR study. Mater. Struct. 45(1-2), 297-308.

Kemna, A., Binley, A., Cassiani, G., Niederleithinger, E., Revil, A., Slater, L., Williams, K.H., Flores-Orozco, A., Haegel, F.-H., Hördt, A., Kruschwitz, S., Leroux, V., Titov K., 2012. An overview of the spectral induced polarization method for near-surface applications. Near Surf. Geophys. 10(6), 453-468.

Kim, B.K., Baek, K., Ko, S.H., Yang, J.W., 2011. Research and field experiences on electrokinetic remediation in South Korea. Sep. Sci. Technol. 79(2), 116-123.

Kim, S.-S., Kim, J.-H., Han, S.-J., 2005. Application of the electrokinetic-Fenton process for the remediation of kaolinite contaminated with phenanthrene. J. Hazard. Mater. 118, 121131.

Koch, K., Kemna, A., Irving, J., Holliger, K., 2010. Impact of controlled changes in grain size and pore space characteristics on the hydraulic conductivity and spectral induced polarization response of "proxies" of saturated alluvial sediments. Hydrol. Earth Syst. Sci. Discuss. 7, $6057-6080$.

Lesmes, D.P., Frye, K.M., 2001. Influence of pore fluid chemistry on the complex conductivity and induced polarization responses of Berea sandstone. J. Geophys. Res. Solid Earth 106(B3), 4079-4090.

Lorenz, P.B., 1969. Surface conductance and electrokinetic properties of kaolinite beds. Clay Clay Miner. 17, 223-231.

Masi, M., Losito, G., 2015. Spectral induced polarization for monitoring electrokinetic remediation processes. J. Appl. Geophys 123, 284-294.

Maurya, P.K., Fiandaca, G., Christiansen, A.V., Auken, E., 2018. Field-scale comparison of frequency-and time-domain spectral induced polarization. Geophys. J. Int. 214(2), 1441-1466.

Mei, L., Chou, T.H., Cheng, Y.S., Huang, M.J., Yeh, L.H., Qian, S., 2016. Electrophoresis of pH-regulated nanoparticles: impact of the Stern layer. Phys. Chem. Chem. Phys. 18(15), $9927-$ 9934.

Mewafy, F.M., Werkema, D.D., Atekwana, E.A., Slater, L.D., Abdel Aal, G., Revil, A., Ntarlagiannis, D., 2013. Evidence that bio-metallic mineral precipitation enhances the complex conductivity response at a hydrocarbon contaminated site. J. Appl. Geophys. 98, $113-123$. 
Morgan, F.D., Lesmes, D.P., 1994. Inversion for dielectric relaxation spectra. J. Chem. Phys. 100(1), 671-681.

Nordsiek, S., Weller, A., 2008. A new approach to fitting induced-polarization spectra. Geophysics 73, F235-F245.

Ntarlagiannis, D., Williams, K.H., Slater, L., Hubbard, S., 2005. Low-frequency electrical response to microbial induced sulfide precipitation. J. Geophys. Res. Biogeosci. 110, G02009. Personna, Y.R., Ntarlagiannis, D., Slater, L., Yee, N., O'Brien, M., Hubbard, S., 2008. Spectral induced polarization and electrodic potential monitoring of microbially mediated iron sulfide transformations. J. Geophys. Res. Biogeosci. 113, G02020.

Pelton, W.H., Ward, S.H., Hallof, P.G., Sill, W.R., Nelson, P.H., 1978. Mineral discrimination and removal of inductive coupling with multifrequency IP. Geophysics 43(3), 588-609.

Reddy, K.R., Cameselle, C., 2009. Electrochemical Remediation Technologies for Polluted Soils. Wiley, Sediments and Groundwater.

Revil, A., Florsch, N., 2010. Determination of permeability from spectral induced polarization in granular media. Geophys. J. Int. 181, 1480-1498.

Ryu, B.G., Park, S.W., Baek, K., Yang, J.S., 2009. Pulsed electrokinetic decontamination of agricultural lands around abandoned mines contaminated with heavy metals. Sep. Sci. Technol. 44(10), 2421-2436.

Schmutz, M., Revil, A., Vaudelet, P., Batzle, M., Viñao, P.F., Werkema, D.D., 2010. Influence of oil saturation upon spectral induced polarization of oil-bearing sands. Geophys. J. Int. 183, $211-224$.

Slater, L.D., Lesmes, D., 2002. IP interpretation in environmental investigations. Geophysics 67(1), 77-88.

Sogorka, D.B., Gabert, H., Sogorka, B., 1998. Emerging technologies for soils contaminated with metals-Electrokinetic remediation. Hazard. Ind. Waste 30, 673-685.

Suthersan, S.S., Payne, F.C., 2004. In Situ Remediation Engineering. CRC Press.

Titov, K., Tarasov, A., Ilyin, Y., Seleznev, N., \& Boyd, A., 2010. Relationships between induced polarization relaxation time and hydraulic properties of sandstone. Geophys. J. Int. 180(3), 1095-1106.

Vanhala, H., Soininen, H., 1995. Laboratory technique for measurement of spectral induced polarization response of soil samples. Geophys. Prospect. 43, 655-676.

Vanhala, H., 1997. Mapping oil-contaminated sand and till with the spectral induced polarization (SIP) method. Geophys. Prospect. 45, 303-326. 
650 Virkutyte, J., Sillanpää,M., Latostenmaa, P., 2002. Electrokinetic soil remediation — critical 651 overview. Sci. Total Environ. 289, 97-121.

652 Vocciante, M., Caretta, A., Bua, L., Bagatin, R., Ferro, S., 2016. Enhancements in 653 ElectroKinetic Remediation Technology: Environmental assessment in comparison with other 654 configurations and consolidated solutions. Chem. Eng. J. 289, 123-134.

655 Weigand, M., Kemna, A., 2016. Debye decomposition of time-lapse spectral induced 656 polarisation data. Comput. Geosci. 86, 34-45.

657 Weller, A., Slater, L., Binley, A., Nordsiek, S., Xu, S., 2015. Permeability prediction based on 658 induced polarization: insights from measurements on sandstone and unconsolidated samples 659 spanning awide permeability range. Geophysics 80, D161-D173.

660 West, L.J., Stewart, D.I., Binley, A.M., Shaw, B., 1999. Resistivity imaging of soil during 661 electrokinetic transport. Eng. Geol. 53, 205-215.

662 Williams, K.H., Ntarlagiannis, D., Slater, L.D., Dohnalkova, A., Hubbard, S.S., Banfield, J.F., 663 2005. Geophysical imaging of stimulated microbial biomineralization. Environ. Sci. Technol. $66439,7592-7600$. 
665

666

667

668

669

670

671

672

673

674

675

676

677

678

679

680

681

682

683

684

685

686

687

688

689

690

691

692

693

694

695

696

697

\section{List of captions}

Figure 1. Picture of the experimental apparatus.

Figure 2. Experimental set-up of the electrokinetic treatment (all units are expressed in mm).

$C 1$ and C2 are current carrying electrodes, P1-P5 are potential electrodes and S1-S4 are the investigated sample sections.

Figure 3. Particle size distribution for the analysed samples.

Figure 4. SIP spectra for tap water at $20^{\circ} \mathrm{C}$. The effect of the EM coupling is significant from $100 \mathrm{~Hz}$.

Figure 5. Effect of diffusion (absence of electric field) on amplitude and phase of complex resistivity on the "A" sediment. Mean values are plotted together with the respective experimental error bars. Maximum errors are $0.01 \%$ and 0.01 mrad for amplitude and phase datasets, respectively.

Figure 6. $\mathrm{pH}(\mathrm{a})$ and water saturation ( $b)$ as a function of the distance to the anodic end for the six experiments, before and after the EK treatment. The subscript $O$ (dashed lines) indicates the samples before treatment.

Figure 7. Example of comparison between $D C(a, c)$ and $A C(b, d)$ measurements for the $A 2$ experiment. Mean values are plotted together with the respective experimental error bars.

Figure 8. Mean amplitude values as a function of time for the six experiments: (a) A1, (b) A2, (c) A3, (d) B1, (e) C1 and (f) C2. Mean values are plotted together with the respective experimental error bars.

Figure 9. Mean phase values as a function of time for the six experiments: (a) A1, (b) A2, (c) $A 3,(d) B 1,(e) C 1$ and (f) C2. Mean values are plotted together with the respective experimental error bars.

Figure 10. Observed (markers) and fitted using the Debye decomposition (lines) time-lapse amplitude spectra for the A1 experiment at different sections: $S 1$ (a), S2 (b), S3 (c) and S4 (d). Figure 11. Observed (markers) and fitted using the Debye decomposition (lines) time-lapse phase spectra for the Al experiment at different sections: $S 1$ (a), S2 (b), S3 (c) and $S 4(d)$.

Figure 12. Integral parameters, obtained after inversion of SIP data, as a function of time for the four sections of the Al experiment. (a) DC resistivity, (b) median relaxation time, (c) chargeability and $(d)$ normalized chargeability.

Figure 13. Relaxation Time Distribution (RTD) at different time steps for the four sections of the A1 experiment: $S 1(a), S 2(b), S 3(c)$ and $S 4(d)$. 
Figure 1.

699

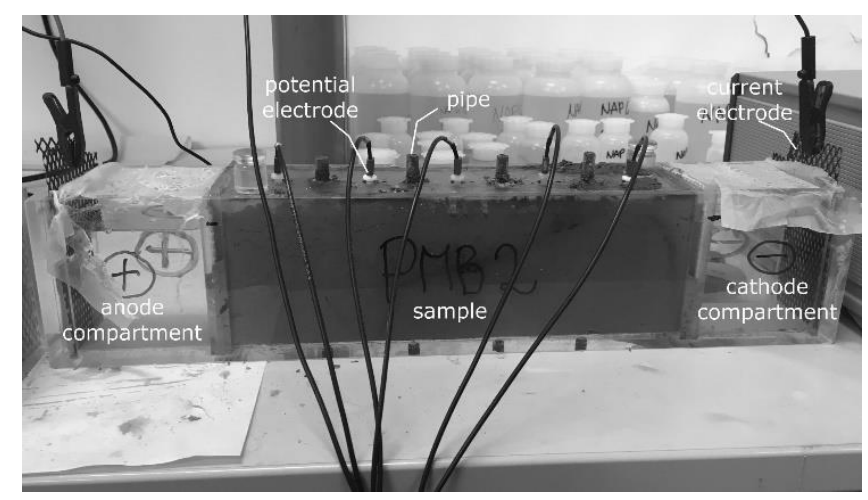

Figure 2.

(a)

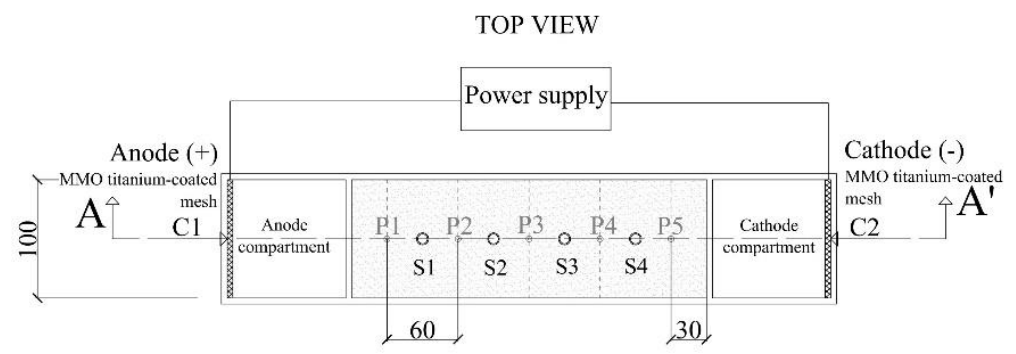

(b)

A-A' CROSS-SECTION

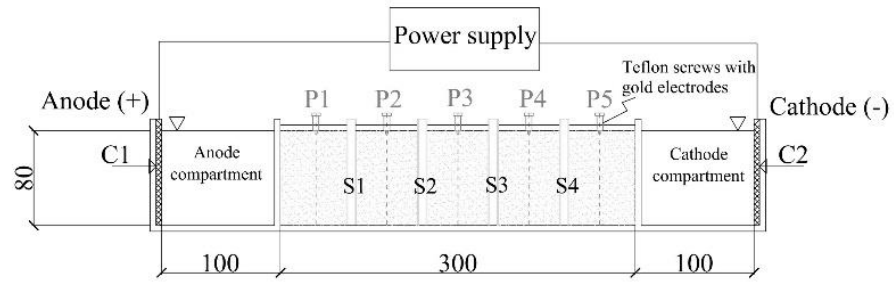

Figure 3.

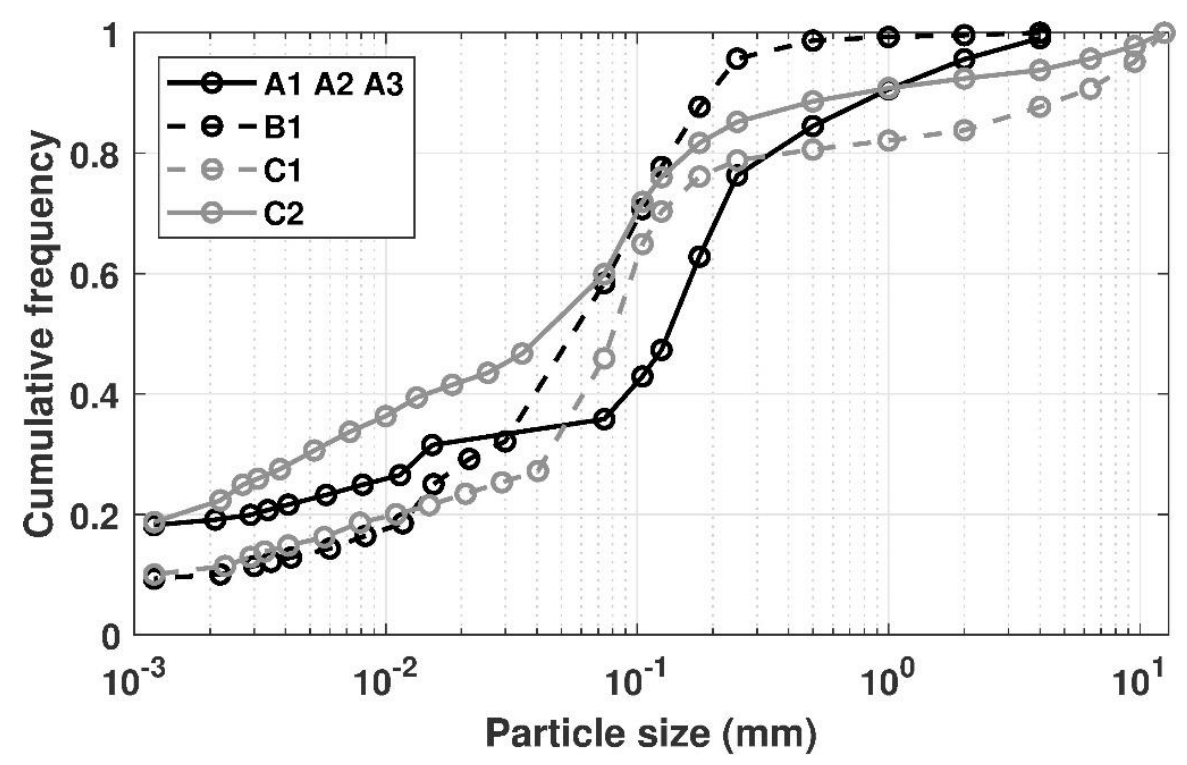


(a)

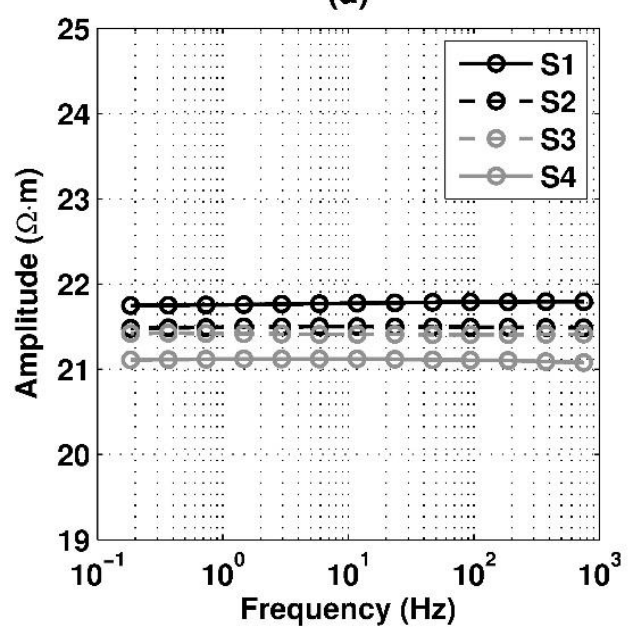

(b)

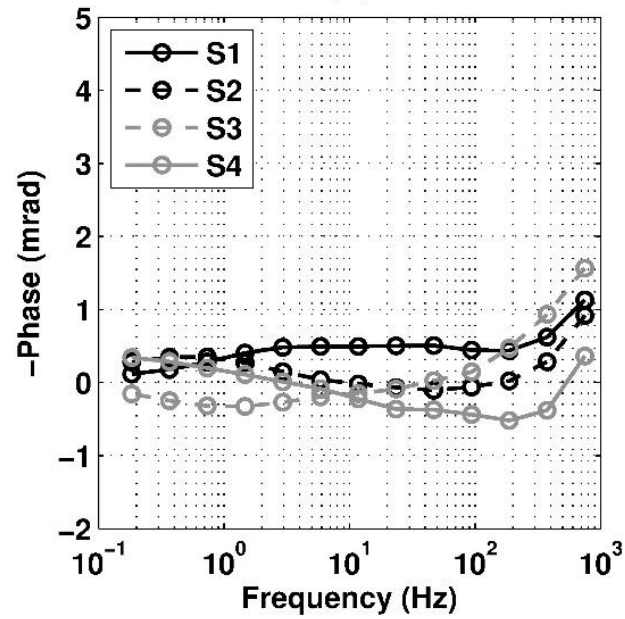

707

Figure 5.

(a)

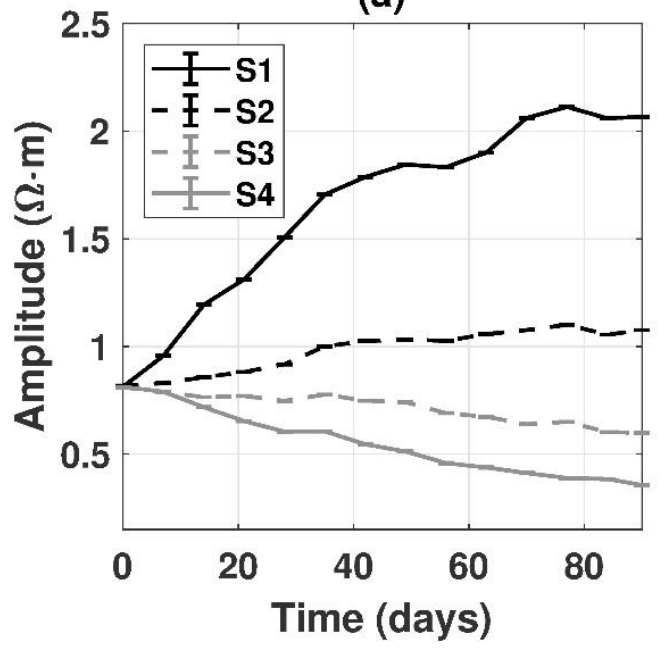

(b)

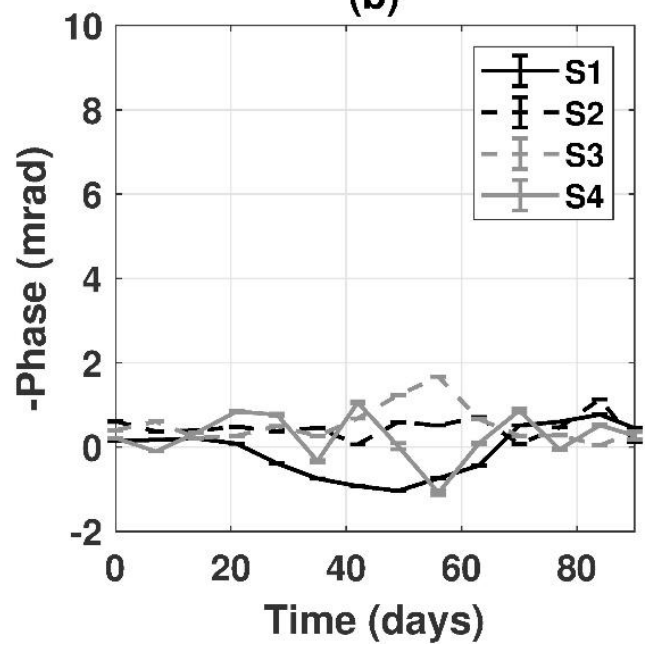

708

709

(a)

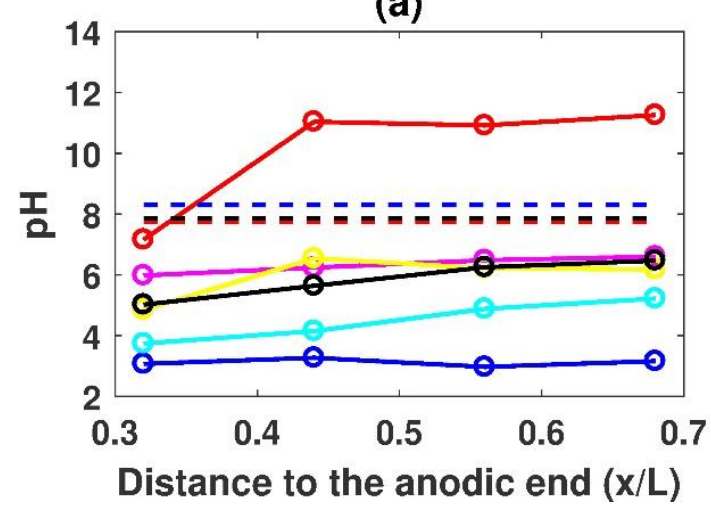

Figure 6.

(b)

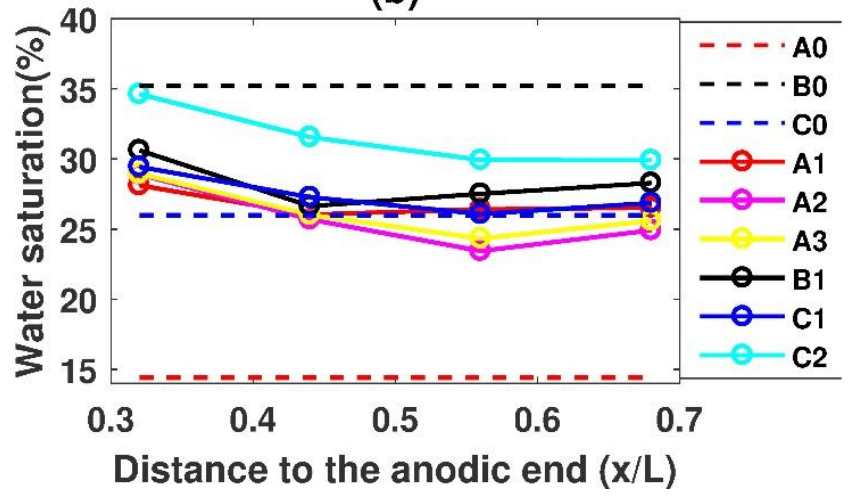


Figure 7.

(a)

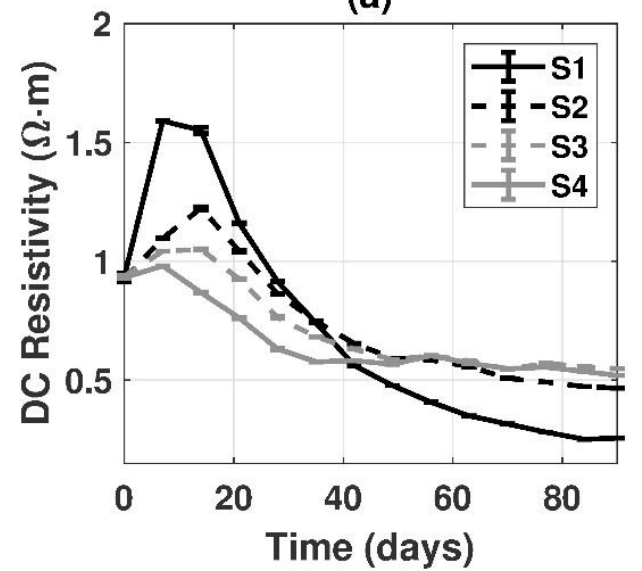

(c)

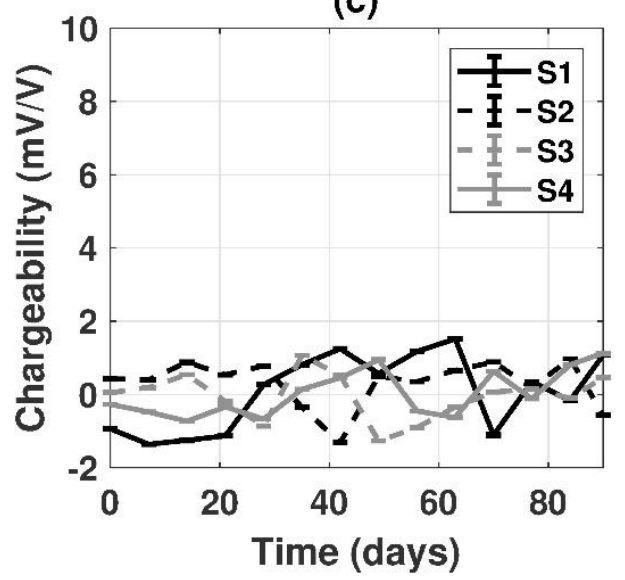

(b)

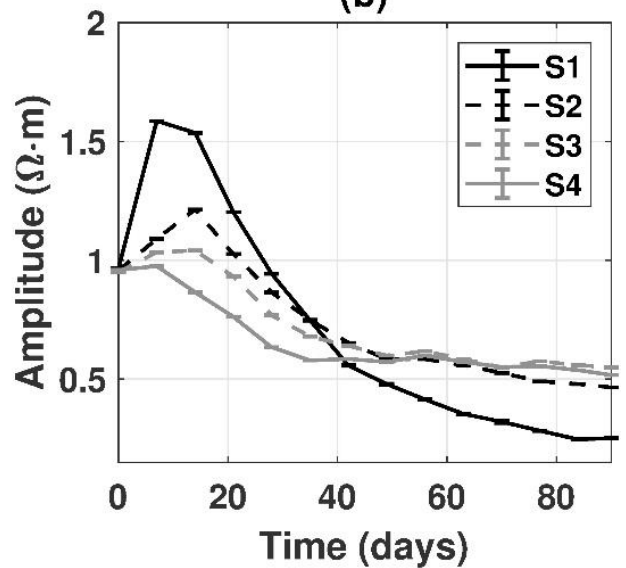

(d)

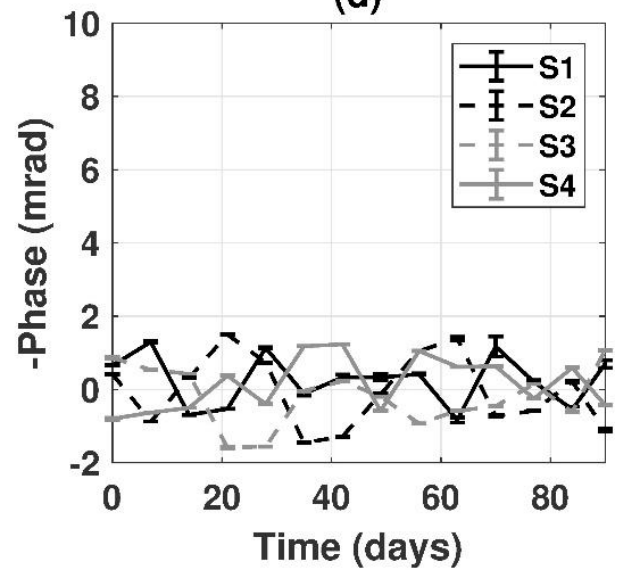


Figure 8.
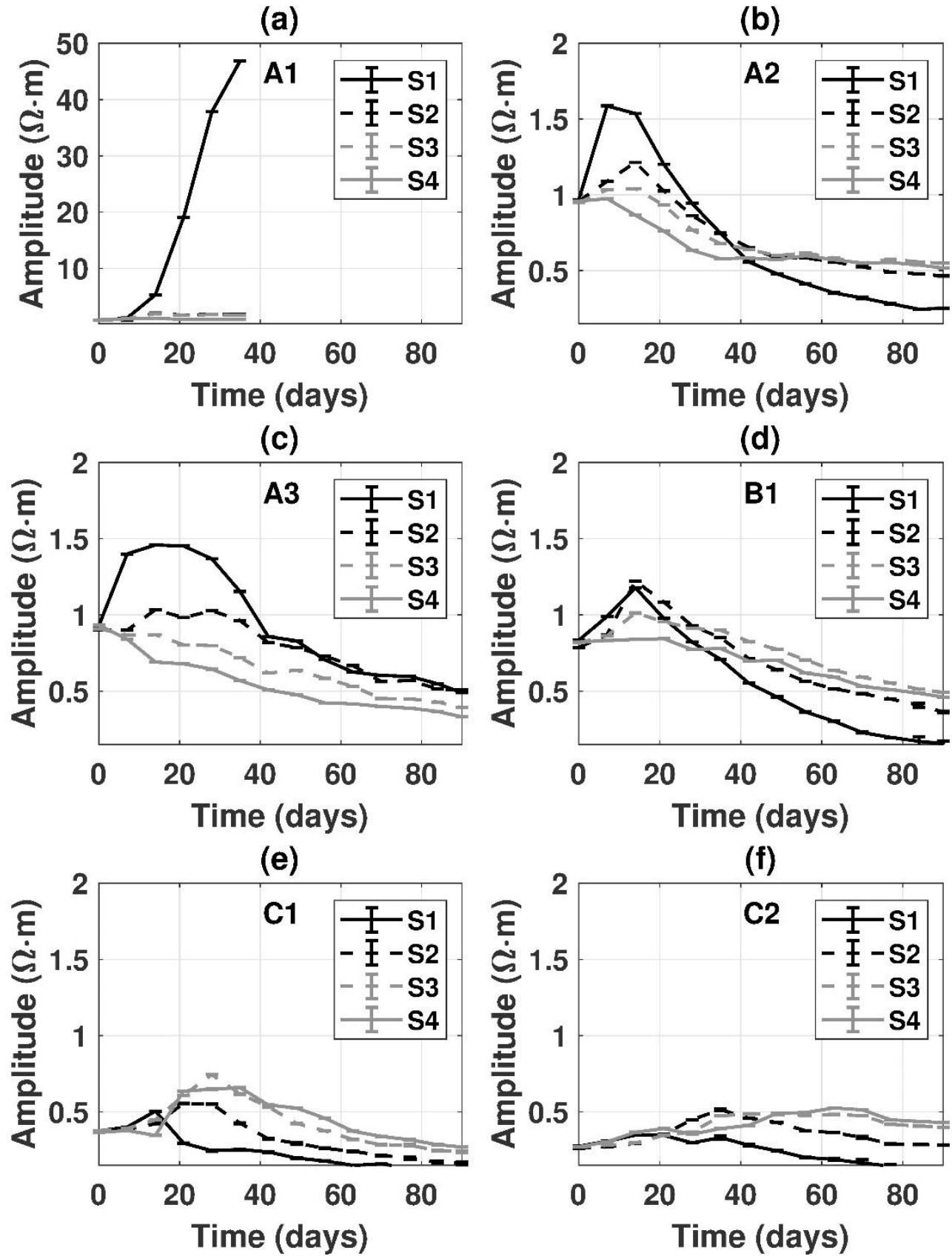
Figure 9.
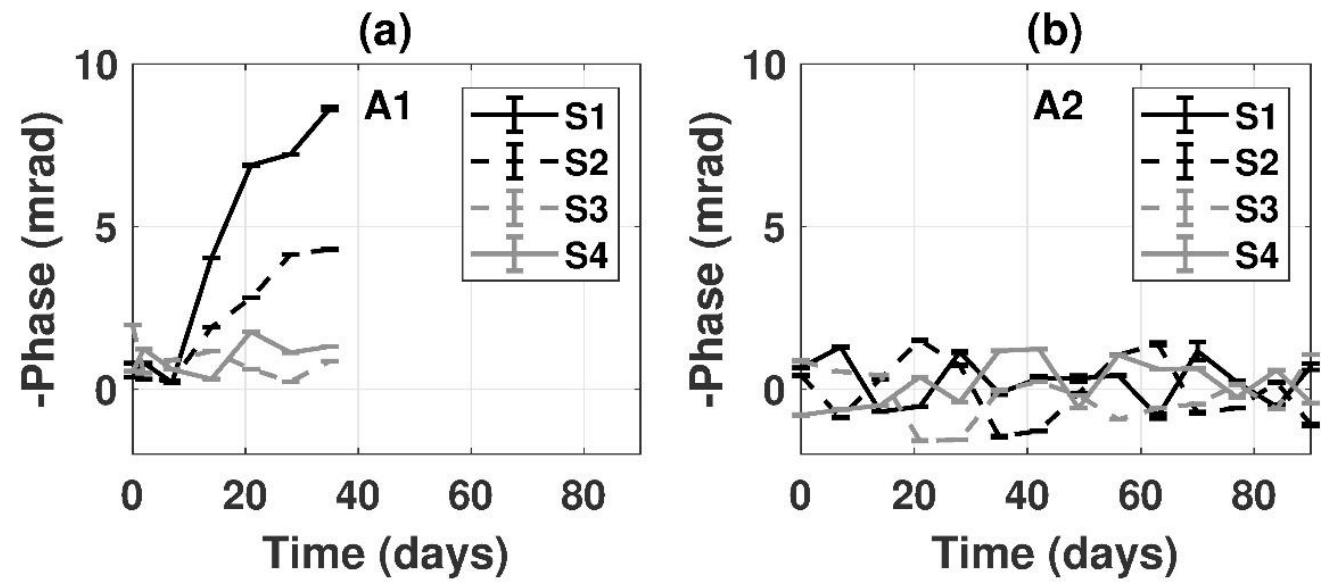

(c)

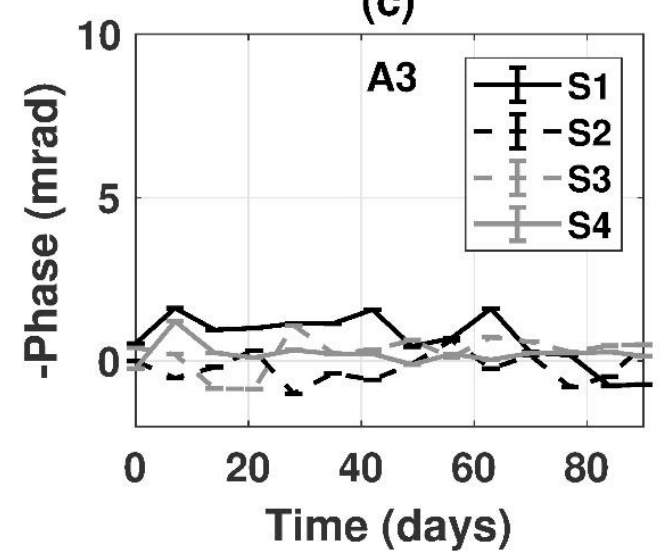

(d)
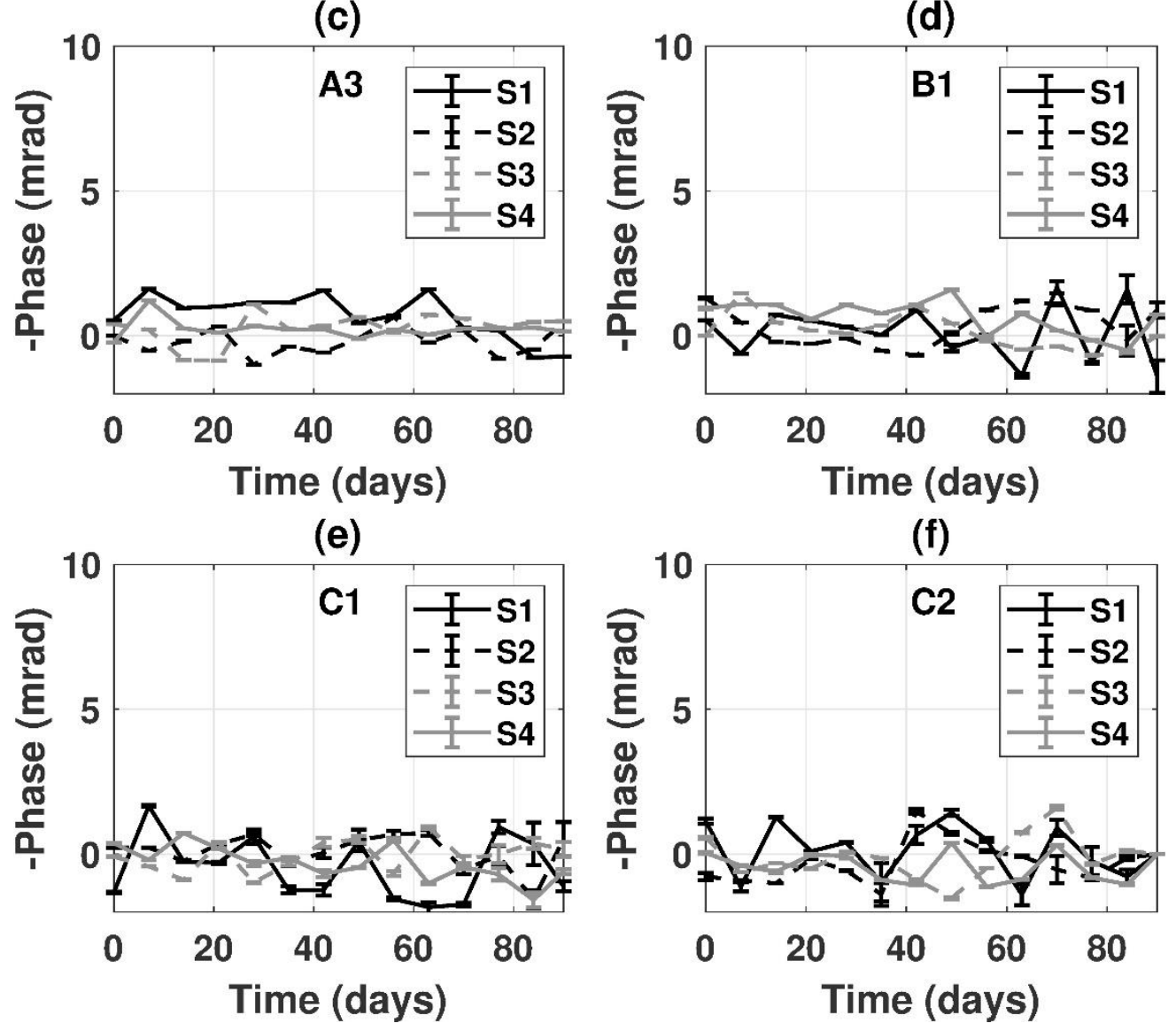
(a)

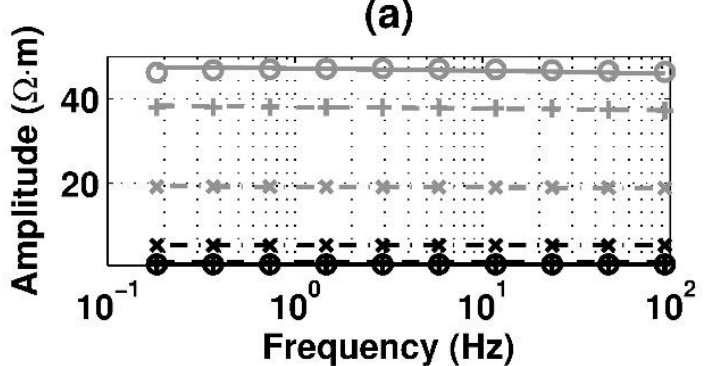

(c)

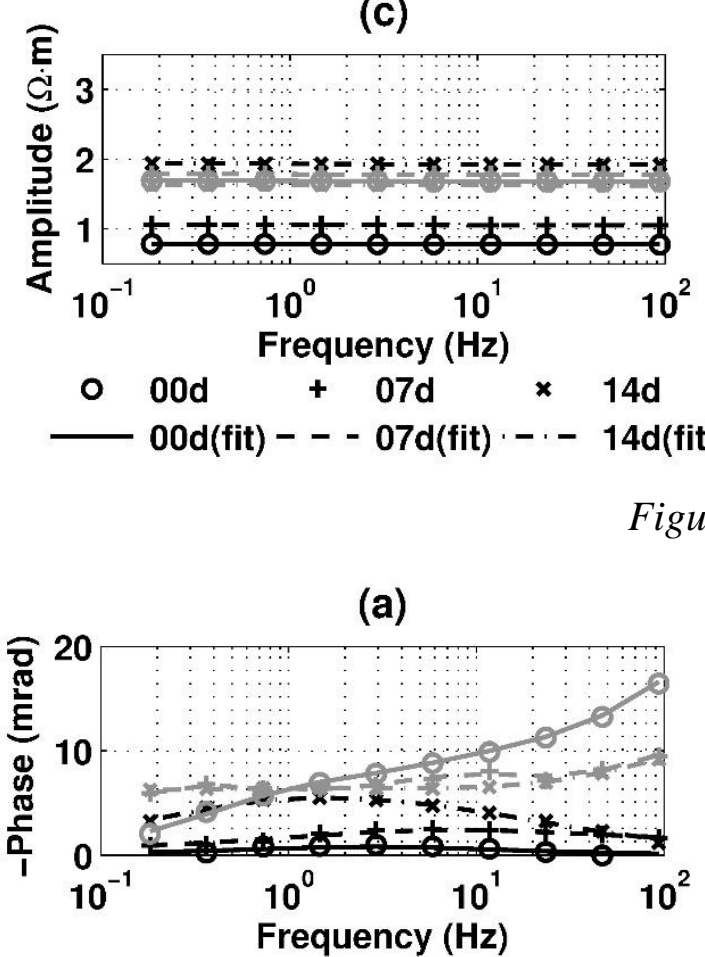

(c)

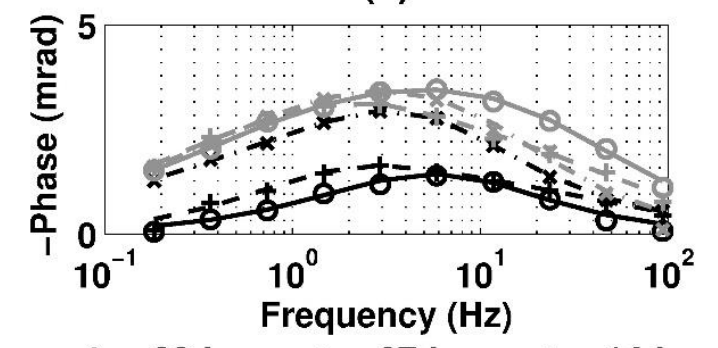

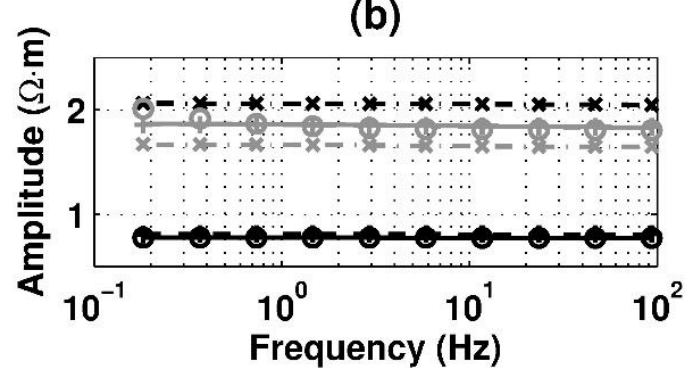

(d)

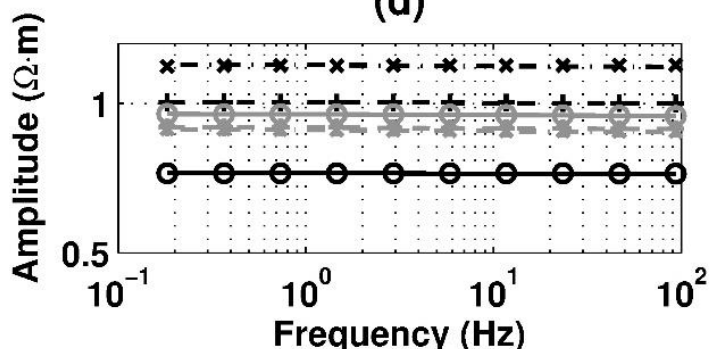

Frequency $(\mathrm{Hz})$

35d $35 d(f i t)$

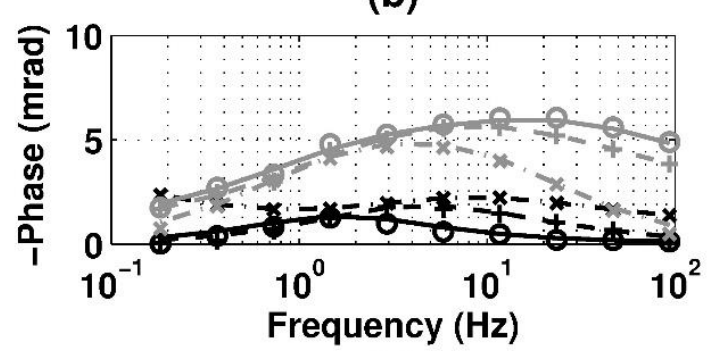

(d)

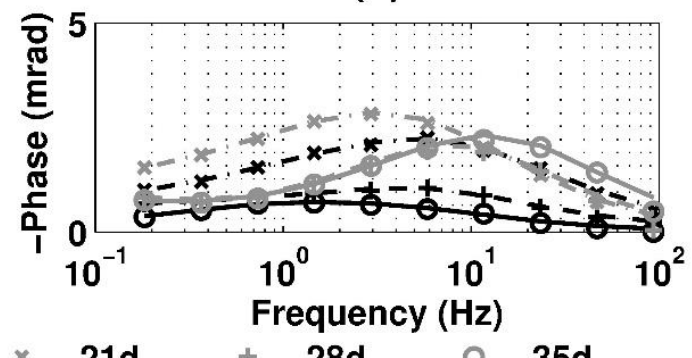


(a)

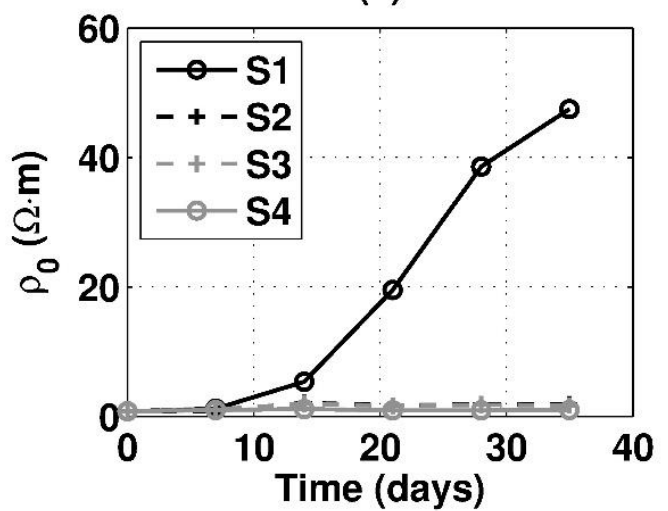

(c)

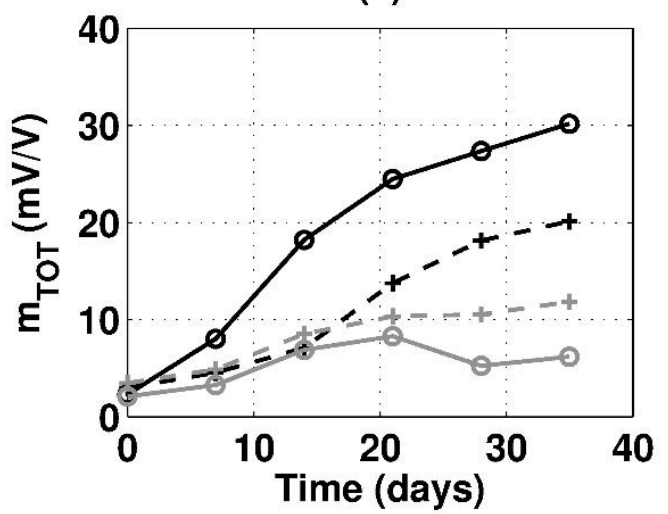

(b)

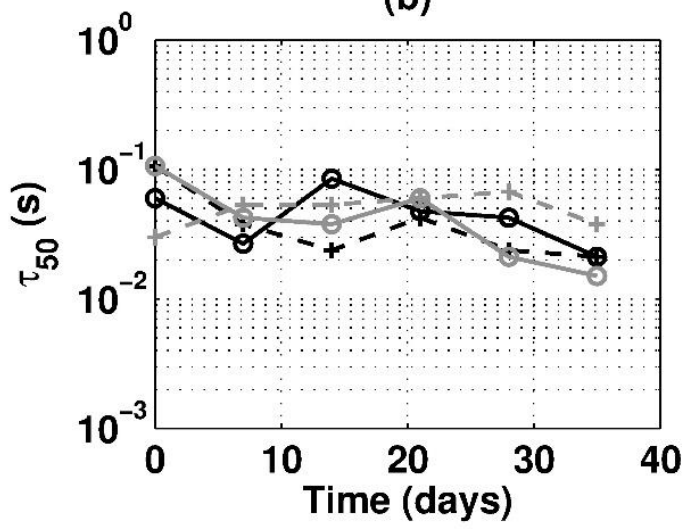

(d)

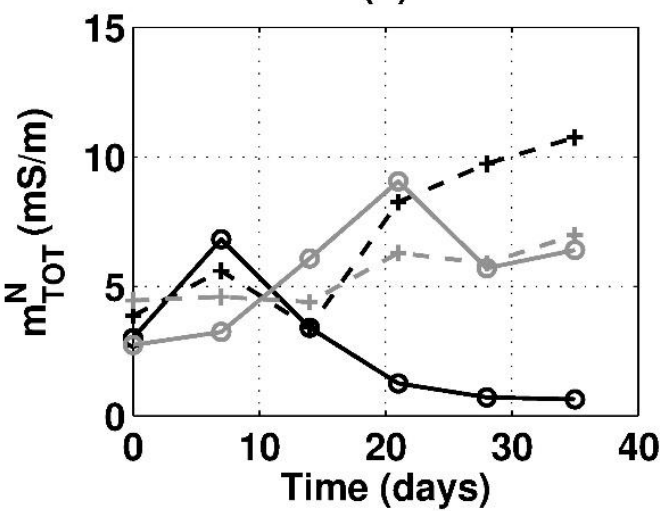

Figure 13.
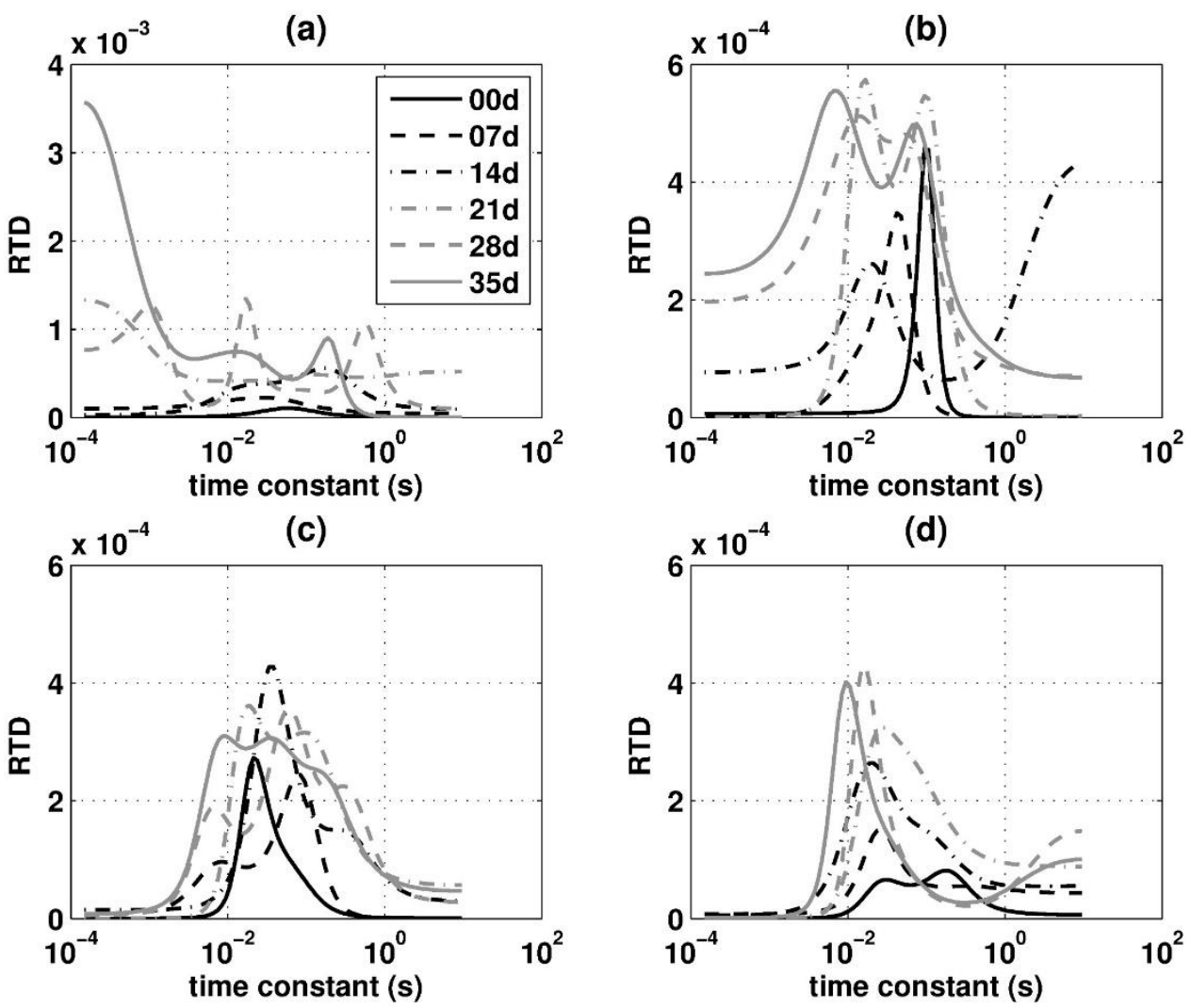